\title{
Medicine as a Driver for the Development of the Regional Economy in the Coal-Mining Region
}

\author{
Evgeniy Kharlampenkov ${ }^{1}$, Irina Kudryashova ${ }^{2, *}$, Mikhail Sokolovsky ${ }^{2}$, and Nataly \\ Zaharova $^{3}$ \\ ${ }^{1}$ Kemerovo State University, 650000, 6, Krasnaya Street, Kemerovo, Russia \\ ${ }^{2}$ Kemerovo State Medical University, Kemerovo, 650029, Voroshilova St., 22A, Kemerovo, Russia \\ ${ }^{3}$ Plekhanov Russian University of Economics, 117997, 36, Stremyanny lane, Moscow, Russia
}

\begin{abstract}
Recently, there has been a reassessment of the impulses and drivers of economic development of such mono raw material subjects of the Russian Federation as Kuzbass. Their resource orientation is replaced by the need to search for new forms and content, including not only "monetization", but also "socialization" of the effects obtained. Taking into account the global trend towards the "servicization" of the economy, the development of IT-technologies, the relevance of this problem in relation to the medicine in Kuzbass is extremely increasing. The article examines the state of medicine in the Kemerovo region, identifies trends in its development, positive and negative factors that promote or hinder sustainable growth. Based on the analysis of foreign approaches to modernizing the sphere of medicine, innovative tools for reforming this industry at the municipal and regional levels are proposed in order to create new jobs, improve the quality of life in Kuzbass. The authors proved the thesis that medicine in Kuzbass can become a driver of the municipal and regional economy development.
\end{abstract}

\section{Introduction}

In a number of scientific publications in recent years, there has been a change in views on the economic development of Kuzbass, a reassessment of the impulses and resources for the development of the territory.

Ten years ago, the industry for the extraction or processing of minerals was considered to be a driver of development in most regions of the country. However, times are changing, taking into account the global trend towards the "servicization" of the economy, the development of IT technologies, when the accelerated development of the service sector or software products provides a significant share in the domestic regional product.

We share the position of Y.A. Fridman, Rechko G.N. and others with regard to the illegality of opposing the resource and innovative development of Kuzbass. As well as the fact that the main problem is not in the rejection of the resource direction of growth, but in the development of its new quality, including not only "monetization", but also "socialization" of the resulting effects, converting innovations not only into profit for investors, but also into the quality of life. [1].

\footnotetext{
${ }^{*}$ Corresponding author: kudrina2007@mail.ru
} 
Among the internationally recognized tools for innovative development, such as "development corridors", intercity agglomerations, "pull projects", "green cities", "smart cities", etc., it is important to characterize the innovative tools functioning in the field of medicine and health care at the regional level.

There are the biomedical cluster created in 2014, medical centers (Federal State Budgetary Scientific Institution "Research Institute for Complex Issues of Cardiovascular Diseases”, Miners' Health Center, clinics of the Kemerovo State Medical University based on the Novokuznetsk State Pedagogical University, Regional Clinical Hospital and a number of other medical institutions), Scientific and Education Center (SEC) "Kuzbass", Kuzbass Techno park.

In recent years, such a new institution as Scientific and Education Center "Kuzbass" has realized the function of a driver in the region. The world-class SEC "Kuzbass" was created in 2019 as a joint program for the entire region to increase the competitiveness of Russian goods and services in world markets for the development of projects and programs for the advanced development and transition of the economy of the Kemerovo region - Kuzbass to a new technological order. It was also designed to assist the regional state authorities in developing an effective management system for the synchronization of the processes of research, innovation, production and market launch, ensuring the transfer of rights and intellectual property objects of scientific and educational organizations of the Kemerovo region - Kuzbass.

As a part of the new "branding" of Kuzbass, SEC "Kuzbass" is intended to become a locomotive for the progressive development of not only the scientific and educational component of the regional economy, but also an important catalyst for the development of business, including small and medium-sized businesses that had previously fled from the region. Among the nine scientific research prospects of the SEC "Kuzbass", priority is given to the direction "Creation of the foundations of personalized medicine, high-tech healthcare and health-preserving technologies", assigned to the Kemerovo State Medical University.

\section{Theory}

Among the indicators that have lowered the ratings of the Kemerovo region in the Russian Federation in recent years, it should be noted, in addition to financial, indicators of the social sphere (health care, education, development of socially significant transport, infrastructure and housing and communal services).

Quite often, the quality of healthcare is determined by the number of hospital beds per 1000 people in the region's population. Despite its importance and taking into account the development of modern medical technologies, this indicator is no longer adequate enough and can be replaced by the level of provision of medical institutions with doctors and nurses per 1000 people. Another system-forming indicator reflecting the quality of life not only in the Russian Federation and its constituent entities, but also in most countries of the world, is the share of state and regional health spending in the national budget.

According to the estimates of the Deputy Prime Minister of the Russian Federation Tatyana Golikova, in 2020, health expenditures in Russia, excluding the costs of private medicine, are estimated at about $3.8 \%$ of GDP [2].

According to the study on the topic of spending on medicine around the world by the scientific journal Lancet, about $\$ 570$ is spent on the health of each person in Russia. This is slightly higher than in China and some other developing countries, but lower than in most European countries. Over the past 30 years, this figure has doubled: in the 1990s, it was about $\$ 300$ [2]. At the same time, the GDP of the Russian Federation for the same period, according to forecast estimates, increased almost in 16 times! (from $\$ 91.625$ billion in 1992 to $\$ 1.46$ trillion in 2020) [3]. Provided that there was no population growth in the Russian Federation 
during this period, there is a significant (eightfold) lag in the growth rate of state financing of health care from the dynamics of GDP growth.

Health care spending in Russia is one of the lowest in the world, while the incidence rate is growing. In 2020, the chief pediatrician of Russia, Leonid Roshal, said that the problems of medicine could not be solved without raising the expenditures for it to 5-6\% of GDP [4].

According to his data, against the backdrop of the COVID-19 pandemic in 2020, Russia increased health spending up to $4 \%$ of GDP. However, in subsequent years, funding for Russian medicine will drop to $3.6 \%$ again. At the same time, in developed countries, an average of $8-10 \%$ of GDP is spent on health care [5].

The relevance of this problem has been reinforced by the pandemic that swept the whole world last year, which caused irreversible consequences in the humanitarian sphere and made the need to transform the medical industry one of the top priorities at the present stage. So, according to Russian State Statistics Service, in January-November 2020, mortality per 1000 people was 1.5 times higher than the birth rate in 2019 (14.0 against 9.7 people) and twice the natural population decline (574.8 thousand people in 2020 against 285.7 thousand people in 2019. ) [6].

An important aspect of the territory development is the improvement of life quality, reflecting the degree of satisfaction of material, social and spiritual needs, one of the components of which is the level of the regional health care development.

To ensure the implementation of the strategic priorities of the region's development, the Strategy for the social-and-economic development of the Kemerovo region for the period up to 2035 outlines key principles, among which the most important are related to ensuring social responsibility, environmental friendliness and health of the population, as well as the quality of life, products and services. The new role of the coal industry is reflected in the Clean Coal - Green Kuzbass platform. To achieve the priority for the formation of Kuzbass as a center of high quality of life, indicated by this document, its main components have been identified, among which the most important is the health development center.

According to the national project Healthcare, a children's clinic was opened in Kemerovo in 2020, a polyclinic of the Clinical Oncological Dispensary was put into operation in Novokuznetsk. In addition, the construction of a modern infectious diseases hospital with 250 beds continues in Novokuznetsk; in spring 2021, it will be commissioned [7].

In 2020, 34 feldsher-midwife stations and two medical outpatient clinics were opened in Kuzbass. Eighty one regional ambulance vehicles were replaced. Now the park consists of 235 ambulances. The ground air ambulance service is fully staffed: it includes 13 reanimobiles, with the help of which it is possible to transport extremely seriously ill patients over long distances, when timely evacuation by ground is impossible. From the middle of 2021, helicopter evacuation will be used; 19 helipads have already been prepared for operation in the territories [7].

This year medical organizations received modern equipment, including 10 mobile photofluorographic units and 10 mobile mammographers, 7 digital stationary photofluorographic units and 5 digital stationary mammographers [7].

The economic task of each Russian region is to become self-sufficient, which will allow it economically solve the problems of its own development, attracting investments to the region to create highly competitive enterprises. In this case, the innovative development of the region will allow at the initial stage reducing the volume of transfers coming from the federal budget.

\section{Results and Discussion}

It is clear that Kuzbass will retain the leading position of the coal mining region for many years, but the problem is that most of the Kuzbass coal enterprises are registered either in 
other regions or in other countries, respectively. Taxes from their activities neither go to the region, nor return indirectly in the form of grants or funds allocated for the construction of facilities as part of the implementation of federal programs and projects. Accordingly, the regional authorities need to search for new development drivers based on small and mediumsized businesses that replenish the regional treasury with tax revenues. Tourism and the development of ski resorts have recently become one of these drivers. However, one direction of economic development, the largest share of which is made by small and medium-sized businesses, no matter how attractive it might be, cannot be the only driver of development. Medicine can become the second driver of the region's development.

The healthcare sector reflects one of the main indicators of the life quality in the region, and is the most important factor in the development of human capital.

The modern development of healthcare in the region, as noted in the Strategy, should be based both on modern innovative technologies, digital technologies, and on the development of human and scientific potential of the medical community. The development of health care, according to the top officials of the state, is possible on the basis of public-private partnership, which has proven its effectiveness in a number of regions.

The negative factors create great risks that impede the flow of private business investments in this area. The situation in healthcare in the region is rather complicated and contradictory. Firstly, this is a higher burden on a doctor than the all-Russian one, which is caused by a shortage of doctors in a number of specialties. For example, the specific provision of oncologists per 100 thousand inhabitants is 1.6 times lower than the average for the Russian Federation, surgeons - 1, 31 times, nephrologists - 1.5 times, gastroenterologists 1.3 times, hematologists -1.51 times, ultrasound doctors -1.51 times, the staffing of medical posts is $49.1 \%$ [7]. The situation in the region is not the best with the nursing staff; out of 85 Russian regions, Kuzbass is in the 59th place with the provision of 59.43 nurses per 10,000 population of the region [9]. The difficult situation with medical personnel leads to the fact that the number of bed-days spent in the hospital per one inhabitant of the region in 2016 (2.5 days) was $12 \%$ higher than the average Russian indicator (2.185 days). The number of patient-days spent in day hospital, per one inhabitant of the region (0.072) is $18 \%$ higher than the same average Russian indicator $(0.061)$. Thus, the intensity of treatment of patients remains rather low, and the load on the doctors significantly increases [9].

This led to the fact that for 1 general practitioner working in the health care system in Kuzbass, there are 253 new diagnoses, which is $20.5 \%$ higher than the national average (210 diagnoses / 1 doctor). For 1 infectious disease doctor in the Kemerovo region, there were 832 new diagnoses for some infectious and parasitic diseases (in the Russian Federation - 671), for one endocrinologist - 425 new diagnoses for diseases of the endocrine system, nutritional disorders and metabolic disorders (in the Russian Federation - 299 ) [7]. It should be noted that in recent years there has been a sharp aging of the medical staff, the average age of about $50 \%$ of the medical staff has exceeded 50 years. Despite the fact that there is a medical university and a number of medical colleges in the region, there is no intensive influx of young specialists. This situation leads to the fact that there is practically no reserve of medical personnel in the region to create innovative medical centers, which can be growth points.

However, there are positive aspects in the health care of Kuzbass, for example, in the number of hospital beds per 10 thousand of the population ( 89.9 units); the regional indicators are $10 \%$ higher than the national average ( 81.6 units). This makes it possible to attract patients for treatment from other regions without increasing the bed capacity [7].

As it was noted above, a driver is a mechanism that has and forms certain connections between growth points and other subjects. When forming a driver, it is necessary to take into account in what areas of health care the formation of promising directions of development is planned. This is due to the general situation with diseases in the region and the accumulated experience, treatment methods, and the provision of the material and technical base of health 
care. A large proportion of diseases in the region are occupational diseases, in the nosology the occupational diseases of the joints, tendons and muscles account for $40.66 \%$, vibration disease $-20.98 \%$, sensorineural hearing loss $-19.01 \%$, dust diseases of the respiratory system $-12,45 \%$, occupational infectious diseases $-0.17 \%$ [10]. In terms of the incidence of children and adolescents, diseases of the respiratory system $(26.5 \%)$, eye diseases $(19.5 \%)$, diseases of the musculoskeletal system (11.9\%) take the leading place. In the adult population, diseases of the circulatory system prevail (the proportion among all causes of death is $48.1 \%$ ), neoplasms ( $13.9 \%)$, diseases of the digestive system $(4.8 \%)$, diseases of the respiratory system $(4.5 \%)$, infectious and parasitic diseases $(2.8 \%)$ [11]. This structure of diseases persists for many years, which prompted medical institutions of the region to develop, first of all, technologies for their treatment.

In Kuzbass the leader of the medical industry is the Kuzbass Clinical Cardiological Dispensary named after L.S. Barbarash, which provides medical services to both adults and children, and is a participant of the federal project "Export development of medical services" or medical tourism. The Center has opened an experimental laboratory, the production of bio-prostheses of heart valves and blood vessels, which makes it possible to introduce scientific developments into medical practice quickly.

The Kuzbass Center of Miners' Health Protection also provides high-tech medical care, representing a range of therapeutic and diagnostic medical services carried out in a hospital using complex and unique medical technologies based on modern scientific achievements and provided by highly qualified specialists. The range of this assistance in the center is quite wide and includes, in addition to traumatology and orthopedics, neurosurgery and microsurgery, and obstetrics and gynecology. The center has always been distinguished by a high level of scientific work of its employees, which allows it to involve practicing doctors in the creation of new products and testing of innovations in patient treatment technology.

Novokuznetsk City Clinical Hospital No. 29 can also be referred to the leaders of Kuzbass medical industry, introducing modern medical technologies into treating activity. This medical institution actively uses telemedicine technologies in practice. It is worth noting the great role of Kuzbass Clinical Emergency Hospital named after M.A. Podgorbunsky, which is the base for five departments of Kemerovo State Medical University and Kemerovo Regional Medical College.

These medical institutions are state-owned, but along with them in the region, there are private medical centers based on modern technologies. For example, in Kemerovo there are about 70 medical centers focused on providing a variety of medical care, including modern diagnostic equipment, performing various, including complex operations. There are similar centers in a number of cities in the Kemerovo region.

A driver is a mechanism with multiple vertical and horizontal links that unite multiple actors, both consumers and growth points and actors that make up the driver infrastructure. The clinics integrated into this mechanism get more opportunities for the formation of multifunctional systems for the provision of medical care on the basis of specialization, cooperation in conducting outpatient studies, in solving problems of material and technical supply.

According to the authors, the functioning of this mechanism can be formed on the basis of graph theory, where nodes are "growth points" connected by edges, and the edges (branches) of the graph characterize the interaction of growth points and consumers. The development driver is a mechanism with a combination of territorial integration and intersectoral interaction, which allows stimulating investment processes in the healthcare sector. When creating territorial clusters that play the role of "transmission nodes" in the driver, a synergistic effect arises from the interaction of its participants, which exceeds the similar effect from the functioning of vertically and horizontally integrated structures [13]. 
At first glance, there is still enough time until 2035, but the development and formation of a program for the development of the medical driver should begin now, by 2035 the medical driver of Kuzbass should show positive dynamics, and the "childhood diseases" of its formation should be overcome by 2030 . During this period, in our opinion, the following steps have to be taken:

1. It is necessary, taking into account the current situation, to determine those areas of medicine in which regional health care has certain successes and a high potential for the provision of medical care, taking into account the existing structure of diseases in the region. It is worth noting certain leading directions of Kuzbass physicians in the field of joint arthroplasty, replantation of a limb segment and plastic repairing of extensive soft tissue defects with a flap on micro-anastomoses. Innovative technologies are actively used in the field of cardiology for the replacement of heart valves, kidney transplantation, in the treatment of pathology of the spine and spinal cord, vascular surgery, correction of refractive errors and eye microsurgery, and in pediatric oncology [14]. The mastering of advanced technologies by Kuzbass doctors on the basis of master classes by leading Russian and foreign specialists should expand the possibilities of regional medicine. These areas should become "points of growth" in the Kuzbass medical driver. Naturally, the technologies developed in certain medical institutions should be implemented everywhere, taking into account the territory of the region, the implementation process should be based on the development of a single methodology, the formation of uniform standards with the possibility of broadcasting and implementation in regional hospitals.

2. Cooperation of the scientific potential of medical institutions of the region, including the Kemerovo State Medical University, scientific centers operating in clinics of the region, regardless of the form of ownership, including SMEs, in order to introduce quickly the methods of treating various diseases in medical practice. The main priority of cooperation is the development and implementation of innovative products and technologies in the field of medicine and health protection. Following the example of Finland, it is necessary to create a block "International Business Activity", which will allow the exchange of experience with the leading medical centers of the planet [15]. The development of medicine is impossible without modern equipment. The task of cooperation is to provide an opportunity, based on collective use, to obtain quickly the results of medical research, which allows developing a treatment algorithm [16].

3. A promising direction is the digitalization of healthcare. In the near future, it is necessary to develop information technologies, which are control flows in the medical organization, a type of these technologies is telemedicine. Telemedicine is an audio-visual communication of a patient with a doctor or the community of doctors in real time. This makes possible to make a diagnosis, quickly develop a treatment plan even before the patient enters the clinic at the diagnostic stage, and make sure that by the time the patient enters the clinic, diagnosis and communication are maximized full. This allows creating, according to the experience of other countries, common databases of clinical information of healthcare institutions, especially for patients with chronic diseases who repeatedly visit clinics, and will help to assess the dynamics of the patient's health status depending on the prescribed treatment. The analysis of activity of the biotechnological cluster located in Boston showed that better information, which has novelty properties and allows constructing a treatment algorithm rationally, often arises and is distributed not within the framework of one institution, but in partner associations of clinics located in a region or country [17]. The implementation of this approach presupposes close interaction of polyclinics and hospitals with the provision of a high speed of information exchange on the Internet with a high degree of encryption of data transmission to comply with medical confidentiality. In this direction, it is rational to use the experience of the Dutch company Health Valley Netherlands, which is a broker in a medical driver and provides services based on digital technologies to a community of doctors and 
clinics in the field of testing new drugs, organizing networking for the implementation of innovative treatment methods and resolving legal issues. The introduction of telemedicine requires the solution of a number of legal problems, therefore, at the regional level, it is necessary to adopt legal acts in this area.

4. The development of healthcare has always been closely connected with the transfer of the latest achievements of pharmaceutical science and medical engineering into medical practice. The transition of the Russian medical industry to an innovative development model is the main goal of the state policy of the Russian Federation for the development of the medical industrial complex [18]. An example is medical clusters in Germany. Tuttlingen cluster currently accounts for $50 \%$ of the surgical equipment market. The enterprises of Tuttlingen cluster produce classical surgical instruments, as well as implants, endoscopes, instruments for minimally invasive surgery [19]. In Kuzbass, the pharmaceutical industry and the production of certain types of medical equipment are to be revived in the near future, including both suppliers of medical products with the transition to direct supplies, and centers for the operation and repair of medical equipment with the possibility of training specialists in secondary specialized educational institutions. The creation of a pharma-engineering subcluster in the region is directed to accelerating the introduction of innovations into medical practice. A mechanism should be developed to ensure the introduction of innovative developments in the field of medical engineering and pharmaceuticals with the broad involvement of SME with support for the practical implementation of their developments. An example is the Scottish medical cluster BioDundee, which has developed a program to reduce the process of introducing new drugs and medical technologies from the moment of development to implementation in clinical practice by strengthening the integration and cooperation of participants in the process [20].

5. At the initial stage of regional medicine development, the focus will be on the residents of the region. Then the number of patients will have to increase due to the treatment of residents of other entities, including foreign citizens, which implies the development of medical tourism and hospitality services with the development of infrastructure of specialized hotels and rehabilitation centers, including sanatoriums; and transport infrastructure. Patient treatment is paid from the compulsory or voluntary health insurance funds. This direction of insurance is associated for insurance companies with a high degree of uncertainty, a high level of risk; therefore, it is advisable to expand new insurance products, the development of special insurance programs that allow referring residents of other regions for treatment, including medical tourism. In this case, the target audience is patients who are insured under treatment programs in other regions.

6. From the organizational point of view in order to optimize the time of patient treatment, it is necessary to develop a well-functioning system of medical logistics, including the processes of routing the patient's movement and medical support using digital tools. According to the decision of the International Committee of the Red Cross, the term "medical logistics" is used to refer to planning, management, control of the flow efficiency, transportation and storage of pharmaceuticals, medical and surgical supplies, medical devices and equipment necessary to ensure the work of personnel in medical institutions, as well as sanatoriums and pharmacies [21]. The main goal of healthcare remains the patient's health, in accordance with this, within the framework of the implementation of the model of integrated medical care using logistics tools, it is necessary to manage the flow of patients. This includes the phased implementation of independent on-line registration of patients for appointments, real-time consultation and patient observation with the use of personal computers and smartphones. In addition, the formation of an electronic passport of the patient's health is involved, which allows, if necessary, inpatient treatment and development a trajectory for sending him to a specific hospital reducing the time the patient spends in the emergency room [22]. In fact, medical logistics is $90 \%$ information technology, and only 
$10 \%$ physical operations related to the delivery of a patient to the "point of medical care" and the logistics of medical institutions. For the regions of Siberia, the problem of both the "last mile" associated with the supply of drugs and medical equipment to clinics and pharmacies located in remote areas is urgent, as well as the problem of the "first mile" associated with the delivery of a patient to a hospital. This problem is connected with the lack of the necessary transport infrastructure. One of the solutions is the revival of medical aviation with the use of drones in the future.

7. The medical institution activity is schematically a two-component structure that includes activities that are valuable for the consumer of medical services (patient) and activities that add value, taking into account the commercialization processes, requiring detailed planning [23]. The creation of a medical driver is associated with modeling the activities of medical organizations and appears when solving various problems arising in the process of managing a medical institution, aimed at optimizing costs and minimizing the time of patient treatment. In this regard, it is necessary to develop cluster management (driver management) aimed at solving strategic and operational tasks of developing a bio-medical cluster. When describing business processes, it is advisable to use BPMN notations, a group of IDEF methodologies, and others. The description of business processes should solve, in our opinion, the following tasks - to standardize the high-level process of providing medical care in hospitals and describe the personifying accounting of material and time costs for its provision [24]. The activity of the driver requires cooperation of the enterprises included in it, this gives a certain synergistic effect, helps to reduce costs [19]. Considering that a driver is a mechanism that connects a large number of components, it is necessary to standardize communications based on the concepts of Workflow or BMP, which allow coordinating repetitive tasks and procedures in terms of accelerating their feasibility and reducing labor intensity based on the regulation of work defining the role of each participant. Moreover, BMP represents an integrated approach to the development of business processes, the optimization of which should reduce the costs of medical institutions. The solution to this problem is possible based on informational support of health care processes [25].

\section{Conclusions}

The article examines the state of medicine in the Kemerovo region, identifies the main trends in its development, positive and negative factors that promote or hinder sustainable growth. Based on the analysis of foreign approaches to modernizing the field of medicine, the authors proposed innovative tools for reforming this industry at the municipal and regional levels in order to accelerate the social-and-economic development of the mining region.

Thus, medicine in Kuzbass can become a driver of regional development in terms of highquality provision of medical services, stabilization of the patients outflow for treatment to other regions and the possibility of attracting patients from other regions and even countries. In addition, it can become an incentive for the formation and acceleration of new industries unusual for the regional economy: medical tourism with a network of sanatoriums and rehabilitation centers, pharmaceutical industry and medical engineering. This will ultimately create new jobs and improve the quality of life in Kuzbass.

\section{References}

1. Yu.A. Fridman, G.N. Rechko, E.Yu. Loginova, Regional Economy. South of Russia, 1(10), 139-149 (2018) 
2. Golikova: healthcare spending in Russia in 2020 will amount to $3.8 \%$ of GDP. URL: https://tass.ru/ekonomika/8788529)

3. Russia's GDP by years: 1991-2020. Volume and dynamics. URL: http://globalfinances.ru/vvp-rossii-po-godam/

4. L. Roshal, Russian Newspaper, 08(27), 16 (2020)

5. Leonid Roshal declared the need to equalize the financing of regional health care. URL: https://lib.medvestnik.ru/

6. Rosstat, Information on the socio-economic situation in Russia (Rosstat, Moscow, 2020)

7. Strategy of socio-economic development of the Kemerovo region for the period up to 2035 (AKO, Kemerovo, 2018)

8. E.A. Islankina, E.S. Kutsenko, F. N. Filina, V. I. Pankevich, Biomedical Clusters in the World: Success Factors and Stories of the Best (HSE University, Moscow, 2019)

9. Irreversible reaction: why does the nursing service exist in Russian medicine as a poor relative? URL: https://vademec.ru/article/nepobratimaya_reaktsiya_pochemu_sestrinskaya_sluzhba_sushchestvuet_v_rossiyskoy_meditsine_na_pravakh

10. A. Khodyrev, Workflow and BPM: What's the Difference? (ELMA, Moscow, 2018)

11. K.S. Kurilov, Healthcare of Kuzbass: yesterday, today, tomorrow (Medkom, Kemerovo, 2020)

12. V. Gryaznevich, RBC, 27(05), 10 (2020)

13. L.N. Ivanova, Journal of Institutional Studies, 2, 120-133 (2015)

14. Zh.V. Meshcheryakova, V.S. Dzekunskas, Bulletin of the North Caucasus Humanitarian Institute, 4, 108-117 (2012)

15. Yu.M. Sigalov, Life+Science, 4, 25-37(2010)

16. S.W. Collins, Prometheus, 26(1), 111-122 (2016)

17. J. Smith, W.W. Powell, Organization Science, 15(1), 5-21 (2004)

18. Biomedical cluster. URL: https://ckr58.ru/clusters/biomedicinskij-klaster

19. K.A. Sokolova, Young Scientist, 4(63), 607-609 (2014)

20. "I'm a Celebrity" eating challenge bugs to tackle malnutrition. URL: https://www.biodundee.co.uk/science-city/news

21. E.P. Zhavoronkov, Medicine and Education in Siberia, 4, 53 (2010)

22. L. Harrington, Hospital logistics gets a check-up. URL: http://www.inboundlogistics.com/articles/features/1208_feature01.shtml

23. Business processes in a medical organization. URL: http://bizguid.ru/biznes-processyv-medicinskoj-organizacii/

24. D.V. Belyshev, Ya. I. Guliev, V.L. Malykh, Medical Information Systems, 5, 78-90 (2014)

25. L.S. Khoroshilova, L.M. Tabakaeva, I.V. Trofimova, Bulletin of the KemSU, 2, 150 (2010) 